\title{
In vitro cellular responses to silicon carbide nanoparticles: impact of physico-chemical features on pro-inflammatory and pro- oxidative effects
}

Jérémie Pourchez, Valérie Forest, Najih Boumahdi, Delphine Boudard, Maura Tomatis, Bice Fubini, Nathalie Herlin-Boime, Yann Leconte, Bernard Guilhot, Michèle Cottier, Philippe Grosseau

\section{J. Pourchez (Corresponding-Author), V. Forest}

Ecole Nationale Supérieure des Mines, CIS-EMSE, LINA EA 4624, F-42023, Saint-Etienne, France

SFR IFRESIS, F-42023, Saint-Etienne, France

e-mail: pourchez@emse.fr Phone: (+33) 477420180 Fax: (+33) 477499694

N. Boumahdi, B. Guilhot, P. Grosseau

Ecole Nationale Supérieure des Mines, SPIN-EMSE, CNRS:FRE3312, LPMG, F42023, Saint-Etienne, France

SFR IFRESIS, F-42023, Saint-Etienne, France

D. Boudard, M. Cottier

Université Jean Monnet, Faculté de Médecine, LINA EA-4624, F-42023, Saint-

Etienne, France

Université de Lyon, F-42023, Saint-Etienne, France

CHU de Saint-Etienne, F-42055, Saint-Etienne, France

SFR IFRESIS, F-42023, Saint-Etienne, France

M. Tomatis, B. Fubini

Dipartimento di Chimica and 'G. Scansetti' Interdepartmental Center for Studies on Asbestos and other Toxic Particulates, Università di Torino, Torino, Italy.

N. Herlin-Boime, Y. Leconte

Laboratoire Francis Perrin, Service des Photons, Atomes et Molécules, CEA-

CNRS URA2453, IRAMIS, CEA SACLAY, F-91191, Gif sur Yvette, France 


\begin{abstract}
Silicon carbide is an extremely hard, wear resistant and thermally stable material with particular photoluminescence and interesting biocompatibility properties. For this reason it is largely employed for industrial applications such as ceramics. More recently nano-sized SiC particles were expected to enlarge their use in several fields such as composite supports, power electronics, biomaterials etc. However, their large-scaled development is restricted by the potential toxicity of nanoparticles related to their manipulation and inhalation. This study aimed at synthesizing (by laser pyrolysis or sol-gel methods), characterizing physico-chemical properties of 6 samples of $\mathrm{SiC}$ nanopowders, then determining their in vitro biological impact(s). Using a macrophage cell line, toxicity was assessed in terms of cell membrane damage (LDH release), inflammatory effect (TNF- $\alpha$ production) and oxidative stress (ROS (Reactive Oxygen Species) generation). None of the six samples showed cytotoxicity while remarkable pro-oxidative reactions and inflammatory response were recorded, whose intensity appears related to the physico-chemical features of nano-sized $\mathrm{SiC}$ particles. In vitro data clearly showed an impact of the extent of nanoparticle surface area and the nature of crystalline phases $(\alpha-\mathrm{SiC} v s . \beta-\mathrm{SiC})$ on the TNF- $\alpha$ production, a role of surface iron on free radical release, and of the oxidation state of the surface on cellular $\mathrm{H}_{2} \mathrm{O}_{2}$ production.
\end{abstract}

Keywords silicon carbide nanoparticles, laser pyrolysis, sol-gel, biological activity, toxicity, macrophage cell line.

\title{
Introduction
}

Silicon carbide $(\mathrm{SiC})$ is a well-known ceramic material with remarkable properties such as high chemical inertness, elevated thermal stability and excellent mechanical properties. As a result, mainly as micro-sized particles, SiC is widely used for many different industrial purposes in the ceramic or composite material field. Moreover, nano-sized $\mathrm{SiC}$ particles are also considered as promising materials for refractory carbide nanostructured ceramics, power electronics or catalysis supports (Melinon et al. 2007; Leconte et al. 2007). More recently, attention was paid to photoluminescence properties which strongly depend on the 
size of SiC nanoparticles (Fan et al. 2008; Kassiba et al. 2002). Thus, several applications using nanoscaled $\mathrm{SiC}$ emerged in life sciences such as the development of biomedical fluorescent probes or delivery systems of chemotherapeutic agents for cancer treatment (Duncan et al. 2006; Botsoa et al. 2008; Tong et al. 2009). All things considered, due to the applications proposed in diverse areas of technology, workers, consumers and patients exposure to $\mathrm{SiC}$ nanoparticles should increase in the next decades.

Toxicological data available in the literature are mainly obtained from experiments conducted on micro-scaled SiC particles or fibers. It has been shown that $\mathrm{SiC}$ dust does not induce harmful effects on tissues, allowing to consider $\mathrm{SiC}$ material as quite biologically inert (Bruch et al. 1993a, 1993b). Conversely, other studies suggest potential adverse effects induced by SiC. On one hand, in vivo exposure to $\mathrm{SiC}$ microparticles triggers lung inflammation (Cullen et al. 1997), granulomas (Vaughan et al. 1993), bronchoalveolar hyperplasia and severe lung fibrotic changes (Akiyama et al. 2007). On the other hand, in vitro responses to $\mathrm{SiC}$ microparticles were characterized by significant cytotoxic and genotoxic effects (Vaughan et al. 1993), reactive oxygen species (ROS) generation (Svensson et al. 1993) and stimulation of pro-inflammatory cytokines production like TNF- $\alpha$ (Cullen et al. 1997). Recent in vitro studies, specifically devoted to SiC nanoparticles, highlighted an accumulation in A549 lung epithelial cells, a major cell redox status disturbance and DNA damage (Barillet et al. 2010a; 2010b). Thus, the authors proposed to reconsider SiC nanoparticles biocompatibility and to handle $\mathrm{SiC}$ nanoparticles with caution until more toxicological information is available.

In this context, to support the growing market of $\mathrm{SiC}$ nanopowders and nanocomposite materials, it seems imperative to study and understand the 
interactions between $\mathrm{SiC}$ nanostructures and living cells. Consequently, we conducted a multidisciplinary study in order to examine the impact of physicochemical parameters of $\mathrm{SiC}$ nanoparticles on in vitro cellular responses. As a matter of fact, a main challenge is the lack of comprehensive data to assess the potential toxicity of $\mathrm{SiC}$ nanoparticles regarding different sizes, surfaces, structures or chemical composition. As these gaps need to be filled, we aimed at identifying physico-chemical properties of $\mathrm{SiC}$ nanoparticles that could affect biological activity and that could be directly related to the toxicity of the nanoparticles. To reach this objective we synthesized at the laboratory scale by the laser pyrolysis and sol-gel processes 6 different $\mathrm{SiC}$ nanoparticles showing different sizes (from 15 to $60 \mathrm{~nm}$ ), crystallographic structures (i.e. $\beta$-SiC corresponding to $\mathrm{SiC}-3 \mathrm{C}$ polytype with or without the presence of $\alpha-\mathrm{SiC}$ corresponding to $\mathrm{SiC}-6 \mathrm{H}$ polytype), variable $\mathrm{C} / \mathrm{Si}$ atomic ratio (i.e. silicon or carbon excess), surface oxidation (i.e. the formation of a silica or an oxycarbide layer around the $\mathrm{SiC}$ grain) or chemical surface impurities (i.e. the quantification of the amount of iron per unit surface). Selectively, we also used during this study a sample of pure $\alpha$-SiC synthesized by mechanical wet-milling technique. In vitro toxicological assessment was carried out using a macrophage cell line (RAW 264.7, a cultured murine macrophage widely used in nanotoxicology studies due to their phagocytosis capacity), in order to determine the cytotoxicity (LDH release), the pro-inflammatory response (TNF- $\alpha$ secretion), and the oxidative stress $\left(\mathrm{H}_{2} \mathrm{O}_{2}\right.$ specific production). The potential to generate free radicals $\mathrm{HO}$, $\mathrm{COO}^{-}$was also investigated in cell free conditions. 


\section{Experimental}

\section{SiC nanoparticle synthesis}

In this study, various $\mathrm{SiC}$ nanopowders were synthesized using two methods: Laser pyrolysis or sol-gel process. $\mathrm{SiC}$ nanoparticles synthesis by continuous $\mathrm{CO}_{2}$ laser pyrolysis has already been reported (Herlin-Boime et al. 2004). This technique is based on the interaction between a powerful laser beam and a mixture of gaseous or liquid precursors (Leconte et al. 2007). Five SiC nanopowders (named LP1 to LP5) have been synthesized by laser pyrolysis of silane $\left(\mathrm{SiH}_{4}\right)$ and acetylene $\left(\mathrm{C}_{2} \mathrm{H}_{2}\right)$ gaseous precursors (Leconte et al. 2007; Cauchetier et al. 1988). The laser radiation is absorbed by silane causing the increase of the reaction temperature. The thermal energy is then transferred to acetylene by collisions leading to molecular dissociation. This decomposition is followed by nucleation and growth of hot nanoparticles emitting in an incandescent flame in the temperature range $1200^{\circ} \mathrm{C}-2000^{\circ} \mathrm{C}$. A rapid cooling at the exit of the reaction zone limits the particle size, which are collected downstream the reactor. The nanoparticles obtained by laser pyrolysis are usually of spherical shape. The control of the synthesis parameters $(\mathrm{C} / \mathrm{Si}$ atomic ratio of the gaseous precursors, reactant flow rates, laser power) leads to the synthesis of $\mathrm{SiC}$ nanoparticles with well-defined chemical composition and degree of crystallization. Moreover, the grain size is controlled by the time of residence in the reaction zone. LP1 nanopowder corresponds to typical nanoparticles of $\beta$-SiC synthesized by laser pyrolysis. Compared to $\mathrm{SiC} \mathrm{LP} 1, \mathrm{SiC} \mathrm{LP} 2$ and LP3 samples correspond to $\mathrm{SiC}$ nanoparticles enriched in carbon and silicon respectively. SiC LP4 and LP5 samples correspond to nanopowders with coarse grains of larger size voluntary obtained during laser synthesis respectively by increasing particles time residence in the reactor (Cauchetier et al. 1988; Tougne et al. 1993) and with a higher laser 
power (Fantoni et al. 1990; Herlin-Boime et al. 2004) allowing the modification of some properties such as grain size and crystallinity.

The synthesis of SiC powder by a sol-gel process has been extensively studied for the last twenty years and used for the production of fine spherical particles of SiC (Hatakaeyama et al. 1990; Seog et al. 1993). This process is a wet-chemical technique starting from a colloidal solution (sol) which contains the precursors of an integrated network (or gel). The sol-gel process generally involves the use of metal alkoxides which undergo hydrolysis and condensation polymerization reactions to form gels. In our case, precursors are PTES (phenyl-triethoxy silane) and TEOS (triethoxy silane) which after hydrolysis and polycondensation form a colloid. After $24 \mathrm{~h}$ at $20^{\circ} \mathrm{C}$, the gel collected is dried $\left(60^{\circ} \mathrm{C} / 48 \mathrm{~h}\right)$ and a thermal treatment is carried out $\left(1500^{\circ} \mathrm{C}\right.$ during $\left.4 \mathrm{~h}\right)$ in argon atmosphere leading to the carbothermal reduction of $\mathrm{SiO}_{2}$. The nanopowder synthesized by this chemical route (named SiC SG) corresponds to spherical nanoparticles of $\beta$-SiC.

\section{SiC nanopowders characterization}

The particles morphology is assessed by electron microscopy in the SEM mode in a field-emission scanning electron microscope (JEOL JSM-6500F). The specific surface area $\left(\mathrm{SSA}, \mathrm{m}^{2} / \mathrm{g}\right)$ was determined by $\mathrm{N}_{2}$ adsorption at $77 \mathrm{~K}$ after out-gassing $2 \mathrm{~h}$ at $200^{\circ} \mathrm{C}$ (Micromeritics ASAP 2000), using the Brunauer-EmmetTeller (B.E.T.) method. The density $\left(\rho, \mathrm{g} / \mathrm{cm}^{3}\right)$ was determined using a gas pycnometer (Micrometrics AccuPyc 1330) working under helium atmosphere. Results are expressed as means of 10 successive measurements on the same sample. Particle diameter (BET size, $\mathrm{nm}$ ) was calculated as BET size $=6000 /(\rho$ $\times$ SSA). X-ray diffraction (XRD) experiments were performed at room temperature to identify the different crystalline phases (Siemens D5000) with a 
semi-quantitative analysis by means of Rietveld method (Siroquant V2.5 software). The crystallite size was calculated from diffractograms using the Scherrer relation (Topaz-4P software). Concentration of constitutive elements ( $\mathrm{Si}$, C) and impurities (O, Fe) was deduced from elemental chemical analysis by inductively coupled plasma spectrometry (ICP, Jobin-Yvon Activa) and LECO $(\mathrm{N} / \mathrm{O}) /(\mathrm{C})$. The oxidation of $\mathrm{SiC}$ nanopowders was characterized by surface analysis by photoelectron spectroscopy (XPS, Thermo VG Thetaprobe).

\section{Free radical release}

The spin trap technique (Fubini et al. 1995), with electron paramagnetic resonance (EPR), has been used to evaluate the potential of $\mathrm{SiC}$ nanoparticles to generate free radicals $\left(\mathrm{HO} \bullet, \mathrm{COO}^{-}\right)$in aqueous suspensions. $45 \mathrm{mg}$ of each powder was suspended in a buffered solution $(0.5 \mathrm{M}$ potassium phosphate buffer, $\mathrm{pH}$ 7.4) containing $0.075 \mathrm{M}$ of DMPO (5-5'-dimethyl-1-pirroline-Noxide) as spin trapping agent. The reaction was started by adding the target molecule: hydrogen peroxide $(0.05 \mathrm{M})$, in order to mimic the contact with $\mathrm{H}_{2} \mathrm{O}_{2}$-rich lysosomal fluids following phagocytosis of the particles by alveolar macrophages, or sodium formate (1.0M) used as a "model" target molecule for homolytic cleavage of a carbon-hydrogen bond The radical yield was progressively measured in a $50 \mu 1$ aliquot of the suspension up to one hour by EPR spectroscopy (Miniscope 100 EPR spectrometer, Magnettech, Germany) using the following parameters: field center $3345 \mathrm{G}$, scan range $120 \mathrm{G}$, microwave power $10 \mathrm{~mW}$, modulation amplitude $1 \mathrm{G}$, scan time $80 \mathrm{~s}$, number of scans 2 . The use of internal standard $(\mathrm{Mn})$ enables radical activity quantification. Each experiment was repeated three times. 


\section{Cell line and culture conditions}

The RAW 264.7 cell line derived from murine peritoneal macrophages (MA) transformed by the AML Virus (Abelson Murine Leukemia Virus) was provided by the ATCC Cell Biology Collection (Promochem LGC, Molsheim). Cells were cultured in Dulbecco's Modified Eagle's Medium (DMEM, Invitrogen), complemented with $10 \%$ of fetal calf serum (FCS, Invitrogen), $1 \%$ penicillinstreptomycin (penicillin 10000 units/mL, streptomycin 10mg/mL; SigmaAldrich, Saint-Quentin Fallavier, France) and incubated at $37^{\circ} \mathrm{C}$ under a $5 \%$ carbon dioxide humidified atmosphere.

Cell viability was determined by trypan blue dye exclusion (FDA, Sigma). For each experiment, as described by Leclerc et al. (2010, 2012), cells were prepared in 96-well plates (100 000 cells/well for TNF- $\alpha$ and LDH assays, and 300000 cells/well for $\mathrm{H}_{2} \mathrm{O}_{2}$ parameter) in $25 \mu \mathrm{L}$ of complete DMEM (DMEMc). Suspensions of SiC powders were prepared in a $75 \mu \mathrm{L}$ volume of DMEMc which were added to the culture and incubated for $90 \mathrm{~min}$ or $24 \mathrm{~h}$ at $37^{\circ} \mathrm{C}$ in a $5 \% \mathrm{CO}_{2}$ atmosphere. The granulometric stability of the suspensions was checked (dynamic light scattering, nanozetasizer, Malvern instrument) before adding to the cell

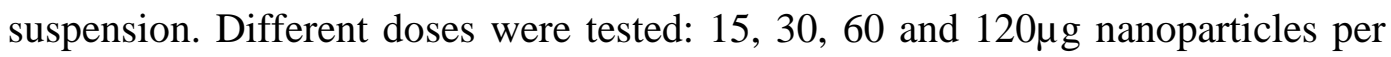
$\mathrm{mL}$ of DMEMc. Negative and positive controls of toxicity, corresponding respectively to the cells incubated alone or incubated with DQ12 quartz (Bruch et al. 2004) were included. Three independent experiments were performed for each condition.

\section{Cytotoxicity assays}

The activity of the lactate dehydrogenase (LDH) released from cells with damaged membranes in the culture supernatant was assessed after a $24 \mathrm{H}$ 
incubation of cells with nanoparticles. The CytoTox-ONE ${ }^{\mathrm{TM}}$ Homogeneous Membrane Integrity Assay (Promega, Charbonnières les bains, France) was used according to the manufacturer's instructions. Detection was performed using a fluorometer (Fluoroskan Ascent, Thermolabsystems), with excitation/emission wavelengths set at 530/590nm. The activity of the released LDH was reported to that of total cellular LDH (measured after the lysis of control cells) and was expressed as a percentage of the control.

\section{Pro-inflammatory response}

Tumor Necrosis Factor alpha (TNF- $\alpha)$ production was assessed in the culture supernatant after a $24 \mathrm{H}$ incubation of cells with nanoparticles. A commercial ELISA Kit (Quantikine® ${ }^{\circledR}$ Mouse TNF- $\alpha$ Immunoassay, R\&D Systems, Lille, France) was used according to the manufacturer's instructions. The optical density of each well was determined using a microplate reader (Multiskan RC, Thermolabsystems, Helsinki, Finland) set to 450nm. A standard curve was established and results were expressed in $\mathrm{pg} / \mathrm{mL}$ of TNF- $\alpha$.

\section{Oxidative stress and $\mathrm{H}_{2} \mathrm{O}_{2}$ secretion}

Acute oxidative stress was assessed by the production of $\mathrm{H}_{2} \mathrm{O}_{2}$ due to cellular stress (ROS parameter) in the condition of a 90 min short term interaction with nanoparticles. Macrophages $\left(3.10^{5} \mathrm{MA} /\right.$ well in a 96 well plate) were incubated in their culture medium at $37^{\circ} \mathrm{C}$ under a $5 \% \mathrm{CO}_{2}$ atmosphere with the different $\mathrm{SiC}$ particle solutions. After this cell time contact, hydrogen peroxide $\mathrm{H}_{2} \mathrm{O}_{2}$ production was measured according to the protocol of De la Harpe and Nathan (De la Harpe et al. 1985). Briefly, KRPG buffer, containing a mixture of scopoletin $(30 \mu \mathrm{M})$, $\mathrm{NaN}_{3}(1 \mathrm{mM})$ and horseradish peroxidase (1 unit pupurogallin/ml HPO) was added 
to cells. Over a $90 \mathrm{~min}$ period, fluorimetric determination $(355 / 460 \mathrm{~nm}$ excitation/emission wavelengths) of scopoletin oxidation, catalyzed by horseradish peroxidase was measured (Fluoroscan Multiskan). Results were expressed as the quantity of $\mathrm{H}_{2} \mathrm{O}_{2}$ released by cells ( $\mathrm{nmol} \mathrm{H}_{2} \mathrm{O}_{2} / 10^{6} \mathrm{MA}$ ).

\section{Statistical analysis}

Results are expressed as means of three independent experiments. Statistical significance was declared when $\mathrm{p}<0.05$ as determined using a Student test.

\section{Results and discussion}

\section{Physico-chemical characterization of SiC nanoparticles}

The 6 nanopowders of $\beta$-SiC (with sometimes the presence of minor $\alpha$-SiC crystalline phase) were produced at the laboratory scale by sol-gel or laser pyrolysis techniques, while we selectively used a sample of pure $\alpha$-SiC synthetized by mechanical wet-milling. All characterization data are summarized in Table 1 . The density was quite the same for the different nanopowders ranging from 3 to $3.2 \mathrm{~g} / \mathrm{cm}^{3}$. All batches of $\beta-\mathrm{SiC}$ and $\alpha-\mathrm{SiC}$ nanoparticles exhibited spherical morphology as illustrated in Figure 1A.

The 3 nanopowders LP1, LP2 and LP3 showed very similar features in terms of size and crystallographic structure: $\beta$-SiC pure cubic phase (SiC-3C polytype), SSA from 125 to $140 \mathrm{~m}^{2} / \mathrm{g}$, BET size from 14 to $15 \mathrm{~nm}$ and crystallite size of $4 \mathrm{~nm}$. The difference between the BET size and the crystallite size indicated the existence of polycrystalline nanoparticles often observed for this particle size. These 3 nanoparticles mainly differed in their $\mathrm{C} / \mathrm{Si}$ atomic ratio (LP1 is stoichiometric $\mathrm{C} / \mathrm{Si}=1$, whereas $\mathrm{LP} 2$ showed a carbon excess $\mathrm{C} / \mathrm{Si}=1.21$ and $\mathrm{LP} 3$ a 
silicon excess $\mathrm{C} / \mathrm{Si}=0.81$ ) and inducing a difference in their surface chemical composition: LP3 nanopowder appeared more oxidized (mainly due to the excess of silicium) and contained more iron impurities than LP1 and LP2 (i.e. 7-8\% vs. $14 \%$ of O1s, and 100-200ppm vs. 605ppm of iron). Let us note that the difference in chemical composition in the LP1 to LP5 samples was in good agreement with the density measurements: only the stoichiometric sample LP1 exhibited the theoretical density of $\mathrm{SiC}$ (i.e. 3.2). The others samples showed a slightly lower density correlated to the presence of phases with lower density (carbon or oxides). Another point concerns the presence of iron impurities in these LP samples. As the synthesis by itself occured in a wall free zone, the presence of iron in the nanoparticles may tentatively be attributed to interaction of highly abrasive $\mathrm{SiC}$ nanoparticles with metallic walls and filters of the collection zone where the particles are trapped.

The second part of the nanoparticles range synthesized by laser pyrolysis (LP4 and LP5) was composed of $\beta$-SiC particles having the same $\mathrm{C} / \mathrm{Si}$ ratio of 0.88 (i.e. with a silicon excess) with increasing BET diameters $(37 \mathrm{~nm}$ for LP4 vs. 59nm for LP5), SSA $\left(52 \mathrm{~m}^{2} / \mathrm{g}\right.$ for LP4 vs. $33 \mathrm{~m}^{2} / \mathrm{g}$ for LP5), and crystallite size (16nm for LP4 vs. 26nm for LP5). In this case, the difference between the BET size and the crystallite size was too low to indicate the existence of polycrystalline nanoparticles, and was mainly due to stacking faults of cubic SiC nanograins (Figure 1B). Moreover, the presence of $\alpha$-SiC hexagonal phase $(\mathrm{SiC}-6 \mathrm{H}<10 \%)$ and iron impurities (around 500ppm) was emphasized for both LP4 and LP5. The presence of SiC-6H phase was not a surprise as this crystalline phase is commonly observed in thin films (Colder, 2005) or gas-phase synthesized nanoparticles (Leconte et al. 2008; Tougne et al. 1993) where stacking faults can be observed within cubic $\mathrm{SiC}$ nanograins or crystallites. Thus, in the present case, the presence 
of $6 \mathrm{H}$ phase in $\mathrm{XRD}$ diagrams does not relate to a mixture of $3 \mathrm{C}$ nanograins with $6 \mathrm{H}$ grains, but to extended crystalline defects within the 3C grains (Figure 1B Leconte et al. 2008). Besides, LP5 exhibited a high oxidation state compared to LP4 ( $22 \%$ vs. $8 \%$ of O1s detected at the nanoparticle surface).

The batch of nanoparticles produced by the sol-gel technique showed similar crystallographic structure than LP4/LP5 (i.e. $\beta$-SiC corresponding to cubic SiC$3 \mathrm{C}$ polytype with the presence of $\alpha$-SiC corresponding to hexagonal $\mathrm{SiC}-6 \mathrm{H}$ polytype lower than $10 \%$ ) and $\mathrm{C} / \mathrm{Si}$ ratio (i.e. $\mathrm{C} / \mathrm{Si}$ equal to 0.88 ), but with $\mathrm{BET}$ size and SSA similar to that of LP1/LP2/LP3 (i.e BET size of 15nm and SSA of $125 \mathrm{~m}^{2} / \mathrm{g}$ ). The $\mathrm{SG}$ nanoparticles also showed a high purity (no iron detected) and a very low oxidation of $\mathrm{Si}$ atoms ( $8 \%$ of $\mathrm{O} 1 \mathrm{~s})$ at the nanoparticles surface.

Finally, we used also a sample of pure $\alpha$-SiC nanoparticles (named $\mathrm{M}$ ) in order to highlight the impact of the nature of the crystalline phase on the in vitro responses. The high amount of iron impurities (2830 ppm) was in good accordance with the mechanical wet-milling technique used to synthesize this powder. As a matter of fact, LP1/LP2/LP3 are pure $\beta$-SiC (SiC-3C polytype), SG/LP4/LP5 showed the presence of $\alpha-\mathrm{SiC} \mathrm{SiC-6H}$ polytype $<10 \%$ ), and the M sample corresponded to a pure $\alpha-\mathrm{SiC}$ ( $\mathrm{SiC}-6 \mathrm{H}$ polytype).

\section{In vitro cellular responses}

The biological activity of SiC nanoparticles was evaluated on a macrophage cell line using 4 different cellular and molecular parameters: LDH release reflecting the cytotoxicity and especially the integrity of the cell membrane (Figure 2), TNF- $\alpha$ production assessing the inflammatory response (Figure 3), acute oxidative stress followed by the $\mathrm{H}_{2} \mathrm{O}_{2}$ cellular production (Figure 4) and the 
capacity of nanoparticles to generate free radicals in cell free conditions (Figure $5)$.

Firstly, no effect was observed concerning the percentage of released LDH (Figure 2). All values in presence of $\mathrm{SiC}$ nanoparticles were at the same level as the negative control (i.e. cells without nanoparticle contact), supporting the conclusion that all $\mathrm{SiC}$ nanoparticles studied were not cytotoxic. Only the positive control (i.e. DQ12 quartz) showed a significantly enhanced and dose-dependent LDH release.

Three different behaviors were observed concerning the pro-inflammatory response induced by $\mathrm{SiC}$ nanoparticles. Figure $3 \mathrm{~A}$ clearly shows that a strong variation in TNF- $\alpha$ concentration and a dose-response relationship occured when the M and SG nanoparticles were incubated for $24 \mathrm{H}$ with macrophages. The proinflammatory effect induced by the SG nanoparticles was quite similar to that of the DQ12 quartz used in this study as a positive control, while the proinflammatory effect induced by $\mathrm{M}$ was constant and significantly higher than both SG and DQ12. An intermediate pro-inflammatory response is observed for LP4 and LP5 with a significant but moderate increase of TNF- $\alpha$ production. Finally, LP1, LP2 and LP3 exhibited no pro-inflammatory effect as the TNF- $\alpha$ production remains similar to that of the negative control (i.e. cells incubated without nanoparticles).

As reported by Figure 4, LP1, LP2 and LP3 nanoparticles induced little or no oxidative stress $\left(50 \mathrm{nmol}<\mathrm{n} \mathrm{H}_{2} \mathrm{O}_{2}<100 \mathrm{nmol}\right.$ ) while the $\mathrm{H}_{2} \mathrm{O}_{2}$ production was higher for LP4 and SG nanoparticles (50nmol $<\mathrm{n} \mathrm{H}_{2} \mathrm{O}_{2}<180 \mathrm{nmol}$ ). The most important acute oxidative stress appeared for LP5 (150nmol $<\mathrm{n} \mathrm{H}_{2} \mathrm{O}_{2}<$ 250nmol). Finally, in cell free conditions, no radical release was observed for LP1 and SG. LP2 and LP3 were able to generate $\mathrm{COO}^{-}$, but not $\mathrm{HO}^{\circ}$ radicals. 
Significant $\mathrm{HO}^{\bullet}$ radical release was observed for $\mathrm{LP} 4\left(\mathrm{nsHO}{ }^{\bullet}=21 \mathrm{nmol} / \mathrm{m}^{2}\right)$ and more importantly for LP5 (Figure 5). This sample exhibited the highest activity in $\mathrm{COO}^{-\bullet}$ (ns $\mathrm{COO}^{-\bullet}=400 \mathrm{nmol} / \mathrm{m}^{2 *}$ ) and $\mathrm{HO}^{\bullet}$ generation per unit surface $\left(47 \mathrm{nmol} / \mathrm{m}^{2}\right)$. LP5 also contained the higher amount of surface iron (about 11 $\left.\mu \mathrm{g} / \mathrm{m}^{2}\right)$.

\section{Impact of $\mathrm{C} / \mathrm{Si}$ atomic ratio on the in vitro cellular responses}

LP1, LP2 and LP3 were $3 \mathrm{SiC}$ nanoparticles showing similar crystallite size $(4 \mathrm{~nm})$, BET size $(14-15 \mathrm{~nm})$, SSA $\left(125-139 \mathrm{~m}^{2} / \mathrm{g}\right)$, oxidation state of the surface (7-8\% of $\mathrm{O} 1 \mathrm{~s}$ ) but increasing $\mathrm{C} / \mathrm{Si}$ atomic ratio from 0.88 to 1.21 (Table 1). This nanoparticle panel does not differ by their cytotoxicity (no cell membrane impairment detected, Figure 2) and their pro-inflammatory response (TNF- $\alpha$ values at the same level as the negative control, Figure 3A). Thus, no influence of the $\mathrm{C} / \mathrm{Si}$ atomic ratio on the in vitro cellular responses was highlighted.

\section{Impact of SiC nanoparticle crystallite size and crystalline phase on the in vitro cellular responses}

On the one hand, SG and LP1, LP2, LP3 were nanoparticles with identical BET size (14-15nm) and disparate crystallite size (14 for SG vs. 4nm for LP1/LP2/LP3). Indeed, SG was the only SiC nanoparticles for which BET and crystallite size were identical whereas for the other nanoparticles the crystallite size was lower than the BET size. As a result SG was the only mono-crystallite $\mathrm{SiC}$ nanoparticle. Besides, a strong difference on the TNF- $\alpha$ production was observed between on one hand SG and on the other hand LP1, LP2, LP3 (Figure 3A). As a matter of fact, the SG monocrystallite nanoparticles triggered a TNF- $\alpha$ 
production similar to that of quartz DQ12, while SG showed a silicon oxycarbide layer (and not a silica layer) at its surface.

On the other hand the impact of the presence $\alpha$-SiC on the pro-inflammatory response was clearly put in evidence. Based on the range of $\mathrm{SiC}$ nanoparticles synthesized at the laboratory scale, when the presence of $\alpha$-SiC was detected by XRD analysis a moderate or elevated TNF- $\alpha$ production was observed (i.e. SG/LP4/LP5 - Figure 3A) while no pro-inflammatory response was highlighted where the nanoparticles were composed of pure $\beta$-SiC crystalline phase (i.e. LP1/LP2/LP3 - Figure 3A). The use of the sample M confirmed that the $\alpha$-SiC crystalline phase induces a higher TNF- $\alpha$ production by comparison of $\beta$-SiC nanoparticles (data not shown, constant level of TNF- $\alpha$ production at $2000 \pm 220$ $\mathrm{pg} / \mathrm{ml}$ whatever the dose in the range $20-120 \mu \mathrm{g} / \mathrm{ml}$ ). Therefore, it strongly suggests that the crystallite size and the presence of $\beta$-SiC (i.e. SiC-6H hexagonal polytype) play a major role on the pro-inflammatory response.

\section{Impact of nanoparticle specific surface area on the in vitro cellular responses}

Focusing on SG, LP4 and LP5, an influence of SiC nanoparticle surface area was observed on the pro-inflammatory effect. If we express the dose of nanoparticles in surface instead of in mass (Figure 3B), a correlation between the TNF- $\alpha$ production and the $\mathrm{SiC}$ nanoparticles introduced in wells can be highlighted. Indeed, including 10 different points coming from $\mathrm{SiC}$ showing a significant TNF- $\alpha$ production (i.e. SG, LP5 and LP4) a linear correlation was observed $\left(\mathrm{R}^{2}=0.97\right)$. This correlation was obtained for $\beta$-SiC nanoparticles with the presence of $\alpha$-SiC lower than 10\% (i.e. SG, LP5 and LP4), confirming the impact of both the crystalline phase and the SSA. All things considered, the 
specific surface area appears as a key parameter on the pro-inflammatory response when nanoparticles containing $\alpha$-SiC crystalline phase are incubated with macrophages.

\section{Impact of the iron content on nanoparticles surface on the in vitro cellular responses}

An important influence of the iron impurities was highlighted on the capacity of nanoparticles to generate free radicals both in cellular test (Akhtar et al. 2010; Kagan et al. 2006) and in cell free condition (Turci et al. 2011; Ball et al. 2000). Ferrous ions $\left(\mathrm{Fe}^{2+}\right)$ may generate hydroxyl radicals through the Fenton reaction $\left(\mathrm{Fe}^{2+}+\mathrm{H}_{2} \mathrm{O}_{2} \rightarrow \mathrm{Fe}^{3+}+\mathrm{OH}^{-}+\mathrm{HO}^{\bullet}\right)$ (Prousek 2007). Metallic iron $\left(\mathrm{Fe}^{0}\right)$ and ferric ions $\left(\mathrm{Fe}^{3+}\right)$ can produce $\mathrm{HO}^{\bullet}$ radicals through a Fenton-like mechanism where

$\mathrm{Fe}^{2+}$ is generated respectively by oxidation of $\mathrm{Fe}^{0}$ (Keenan et al. 2011) by $\mathrm{O}_{2}$ or $\mathrm{H}_{2} \mathrm{O}_{2}$, mainly at acidic $\mathrm{pH}$, and reduction of $\mathrm{Fe}^{3+}$ by endogenous reductants such as ascorbic acid or superoxide anion. In this context it is not surprising to highlight a correlation between the iron content at the SiC nanoparticles surface and the production of hydroxyl radicals.

\section{Impact of the surface oxidation of SiC nanoparticles on the in vitro cellular responses}

The XPS analysis clearly demonstrated that all $\mathrm{SiC}$ nanoparticles exhibit a more or less important surface oxidation (Table 1). However, results showed that LP5 and LP3 seem to be more oxidized with a formation of a silica phase layer $\left(\mathrm{Si}-\mathrm{O}_{2}\right)$ whereas SG, LP1, LP2 and LP4 rather exhibit the formation of a thin layer of silicon oxycarbide phases $\left(\mathrm{Si}-\mathrm{O}_{\mathrm{x}}-\mathrm{C}_{\mathrm{y}}\right)$. If we compare the biological activity of LP5 and LP4, quite similar in their physico-chemical features except the presence 
of a silica layer for LP5, no specific difference appears concerning the TNF- $\alpha$ production. Thus the nature of the surface oxidation layer (silica $v s$. silicon oxycarbide) does not seem to have a significant influence on the proinflammatory response. Moreover, even if LP5 and LP3 with a silica phase layer induce a significant $\mathrm{H}_{2} \mathrm{O}_{2}$ production, other $\mathrm{SiC}$ nanoparticles having a thin layer of silicon oxycarbide phases (such as LP4) exhibit similar or higher $\mathrm{H}_{2} \mathrm{O}_{2}$ production. As a result, the different kinds of surface oxidation layer of $\mathrm{SiC}$ nanoparticle could partially mediate the $\mathrm{H}_{2} \mathrm{O}_{2}$ cellular production.

\section{Conclusion}

The toxicity of nanoparticles is known to be closely related to their physicochemical characteristics (size, shape, surface area, chemical composition etc...). In order to deepen such a relationship, an accurate physico-chemical characterization of different $\mathrm{SiC}$ nanopowders associated with an in vitro global evaluation of their biological activity were carried out. Results clearly showed the impact of $\mathrm{C} / \mathrm{Si}$ atomic ratio, specific surface area, crystallite size, crystallite phase, surface oxidation and iron impurities on cellular responses. Interestingly, opposite to what happens with other toxic particles, e.g. silica (Fubini et al. 2001), we show here that all the types of $\mathrm{SiC}$ nanoparticles tested did not induce any cytotoxic effect. By contrast cellular responses of variable intensity - related to oxidative stress and inflammation - were observed, depending on the physicochemical features of the nano-sized $\mathrm{SiC}$ particles. Firstly a linear correlation was observed between the surface area of SiC nanoparticles and TNF- $\alpha$ production. The crystallite size and the presence of the $\alpha$-SiC crystalline phase also seemed to have a strong impact on the pro-inflammatory response. Moreover, the different 
kinds of surface oxidation layer of $\mathrm{SiC}$ nanoparticles (presence of silica vs. silicon oxycarbide layer) seemed to partially mediate the $\mathrm{H}_{2} \mathrm{O}_{2}$ cellular production. Finally, the free radical production in acellular conditions seems to be associated to the iron content at the nanoparticles surface. However, opposite to other cases (e.g. silica, asbestos) in which even traces of iron ions are able to trigger the Fenton reaction (Fubini et al. 2001; Turci et al. 2010), for SiC nanoparticles a threshold effect around $11 \mu \mathrm{g} / \mathrm{m}^{2}$ has been observed.

Few studies were devoted to the toxicity of $\mathrm{SiC}$ nanoparticles. The data presented in this paper support the conclusion that the commonly accepted SiC biocompatibility should be reconsidered for nano-sized particles in agreement with recent studies (Barillet et al. 2010a; 2010b). SiC nanoparticles cannot be considered as totally biologically inert materials. Even if SiC nanoparticles do not exert any cytotoxic effects, the limited - though sometimes significant - proinflammatory response and/or oxidative stress suggest a potential toxicity in cellular cultures that should be further investigated.

Further investigations are also necessary to a better understanding of the relationship between $\mathrm{SiC}$ physico-chemical features, cellular responses and the underlying mechanisms. However this multidisciplinary study can be helpful in the frame of the design approach to achieve safer SiC based nanotechnology (Morose et al. 2010). Indeed, it appears more cautious for companies to try to mitigate the potential risks of nanoparticles during the design stage rather than downstream during manufacturing or customer use. This is why, using safer design principles, at least 4 parameters (i.e. surface area, crystallite size, nature of crystallite phase and iron content) should be well-controlled to preserve the desired product functionality but also to reduce at the same time the potential 
hazard of SiC nanoparticles, particularly as far as pro-inflammatory responses and the free radicals release are concerned.

\section{REFERENCES}

Akhtar MJ, Kumar S, Murthy RC, et al. (2010) The primary role of iron-mediated lipid peroxidation in the differential cytotoxicity caused by two varieties of talc nanoparticles on A549 cells and lipid peroxidation inhibitory effect exerted by ascorbic acid. Toxicology In Vitro;24(4):1139-47

Akiyama I, Ogami A, Oyabu T, et al. (2007) Pulmonary effects and biopersistence of deposited silicon carbide whisker after 1-year inhalation in rats. Inhalation toxicology 19(2):141-47

Ball BR, Smith KR, Veranth JM, et al. (2002) Bioavailability of iron from coal fly ash: mechanisms of mobilization and of biological effects. Inhalation Toxicology 12 (4):20925

Barillet S, Jugan M, Laye M, et al. (2010a) In vitro evaluation of SiC nanoparticles impact on A549 pulmonary cells: Cyto-, genotoxicity and oxidative stress. Toxicology letters 198(3):324-30

Barillet S, Simon-Deckers A, Herlin-Boime N, et al. (2010b) Toxicological consequences of $\mathrm{TiO}(2), \mathrm{SiC}$ nanoparticles and multi-walled carbon nanotubes exposure in several mammalian cell types: an in vitro study. Journal of nanoparticle research 12(1):61-73

Botsoa J, Lysenko V, Geloen A, et al. (2008) Application of 3C-SiC quantum dots for living cell imaging. Appl Phys Lett 92(17):173902-3

Bruch J, Rehn B, Song H, et al. (1993a) Toxicological investigations on silicon-carbide. 1 inhalation studies. British journal of industrial medicine 50(9) 797-806

Bruch J, Rehn B, Song H, et al. (1993b) Toxicological investigations on silicon-carbide. 2 in vitro cell tests and long-term injection tests. British journal of industrial medicine 50(9) 807813

Bruch J, Rehn S, Rehn B, et al. (2004) Variation of biological responses to different respirable quartz flours determined by a vector model. Int. J. Hyg. Envir. Heal. 207: 203-16

Cauchetier M, Croix O, Luce M (1988) laser synthesis of silicon carbide powders from silane and hydroxycarbon mixtures. Adv. Ceram. Mater. 3:548-552

Colder H, Rizk R, Morales M, et al. (2005) Influence of substrate temperature on growth of nanocrystalline silicon. J. Appl. Phys. 98:024313

Cullen RT, Miller BG, Davis JMG, et al. (1997) short-term inhalation and in vitro tests as predictors of fiber pathogenicity. Environmental Health perspectives 105(5):1235-40

Delaharpe J, Nathan CF, (1985) A Semi-Automated Micro-Assay for H2o2 Release by HumanBlood Monocytes and Mouse Peritoneal-Macrophages. Journal of Immunological Methods, 78(2):323-336

Duncan R, (2006) Polymer conjugates as anticancer nanomedicines. Nat Rev Cancer. 6(9):688701

Fan J, Li H, Jiang J, et al. (2008) 3C-SiC nanocrystals as fluorescent biological labels. Small 4: 1058-1062

Fantoni R, Borsella E, Piccirillo S, et al. (1990) Laser synthesis and crystallographic characterization of ultrafine SiC powders. J. Mater. Res. 5(1):143-50

Fubini B, Mollo L, Giamello E., (1995) Free radical generation at the solid/liquid interface in iron containing minerals. Free Rad. Res. 23:593-614

Fubini B, Fenoglio I, Elias Z, et al. (2001) Variability of biological responses to silicas: effect of origin, crystallinity, and state of surface on generation of reactive oxygen species and morphological transformation of mammalian cells. J Environ Pathol Toxicol Oncol; 20(1):95-108. 
Hatakeyama F, Kanzaki S, (1990) Synthesis of Monodispersed $\beta$ - Spherical SiC Powder by a SolGel Process. J. Am. Ceram. Soc. 73( 7):2107-2110

Herlin-Boime N, Vicens J, Dufour C, et al. (2004) Flame temperature effect on the structure of $\mathrm{SiC}$ nanoparticles grown by laser pyrolysis. Journal of nanoparticle research 6(1) 63-70

Kagan VE, Tyurina YY, Tyurin VA, et al. (2006) Direct and indirect effects of single walled carbon nanotubes on RAW 264.7 macrophages: role of iron. Toxicology Letters 165(1):88-100.

Kassiba A, Makowska-Janusik M, Bouclé J, et al. (2002) Photoluminescence features on the Raman Spectra of quasi-stoichiometric SiC nanoparticles: Experimental and numerical simulations, Phys Rev B, 66, 155317

Keenan CR, Goth-Goldstein R, Lucas D, et al. (2009). Oxidative stress induced by zero-valent iron nanoparticles and $\mathrm{Fe}(\mathrm{II})$ in human bronchial epithelial cells. Environmental Science $\&$ Technology 43(12):4555-60

Leconte Y, Maskrot H, Combemale L, et al. (2007) Application of the laser pyrolysis to the synthesis of $\mathrm{SiC}, \mathrm{TiC}$ and $\mathrm{ZrC}$ pre-ceramics nanopowders, Journal of analytical and applied pyrolysis79:465-70

Leconte Y., Leparoux M., Portier X., N. et al. (2008) Controlled synthesis of $\beta$-SiC nanopowders with variable stoichiometry using inductively coupled plasma, Plas. Chem. Plas. Proc., 28:233.

Melinon P, Masenelli B, Tournus F, et al. (2007) Playing with carbon and silicon at the nanoscale. Nature Materials 6(7):479-90

Morose G, (2010) The 5 principles of “design for safer nanotechnology”. Journal of cleaner production 18:285-89

Prousek J. (2007) Fenton chemistry in biology and medicine. Pure and Applied Chemistry 79(12):2325-38

Seog IS, Kim CH (1993) Preparation of monodispersed spherical silicon carbide by the sol-gel method. J. Mater. Sci. 28: 3277

Svensson I, Arturson E, leanderson P, et al. (1997) Toxicity in vitro of some silicon carbides and silicon nitrides: whiskers and powders. Am J Ind Med 31:335-43

Tong R, Christian DA, Tang L, et al. (2009) Nanopolymeric therapeutics. MRS Bull 34(6):422-31

Tougne P, Hommel H, Legrand AP, et al. (1993) Evolution of the structure of ultrafine SiC-laser formed powders with synthesis conditions. Diamond Relat. Mater. 2:486

Turci F, Tomatis M, Lesci IG, et al (2010) The iron-related molecular toxicity mechanism of synthetic asbestos nanofibres: a model study for high-aspect-ratio nanoparticles. Chemistry 17(1):350-8.

Vaughan GL, Trently SA, Wilson RB (1993) Pulmonary response, in vivo, to silicon-carbide whiskers, Environmental research 63(2):191-201 
Fig. 1 Size and shape of cluster of SiC nanoparticles LP5 observed by scanning electron microscopy (A) and high-resolution transmission electron microscopy observation with the presence of $\alpha-\mathrm{SiC}$ and $\beta$-SiC due to stacking faults in cubic SiC nanograins (B - Leconte et al., 2008)

A

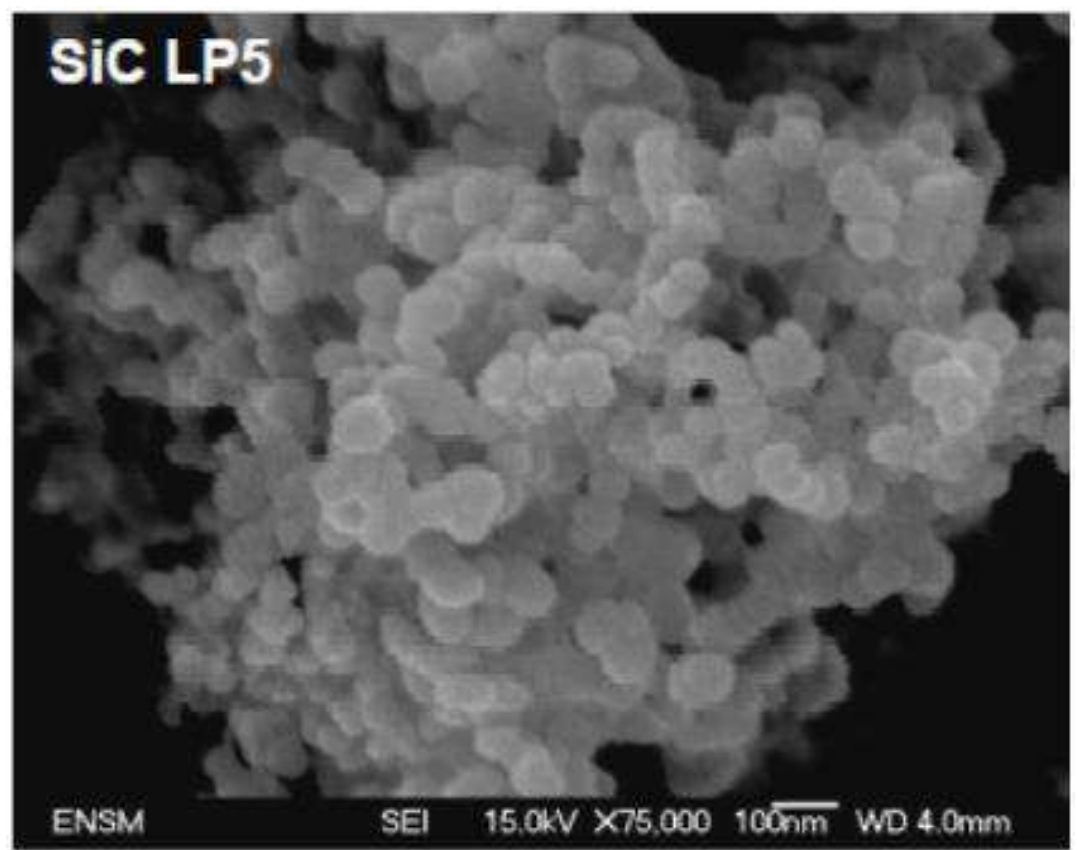

B

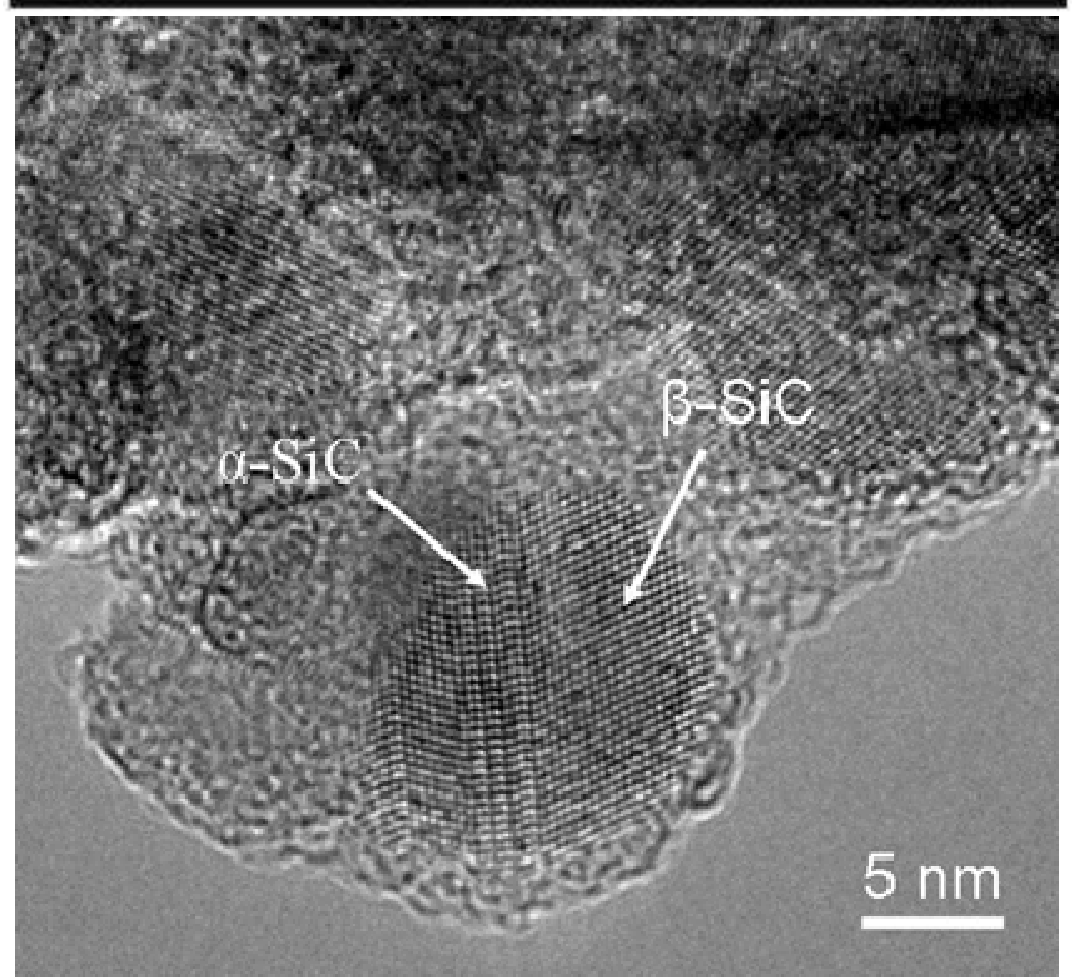


Fig. 2 Cytotoxicity of $\mathrm{SiC}$ nanoparticles determined by the LDH release (reported to that of total cellular LDH measured after control cells lysis). Standard deviation and statistically significant differences from the negative control (cells incubated without nanoparticles) are also indicated: * $\mathrm{p}<0.05, * * \mathrm{p}<0.01$

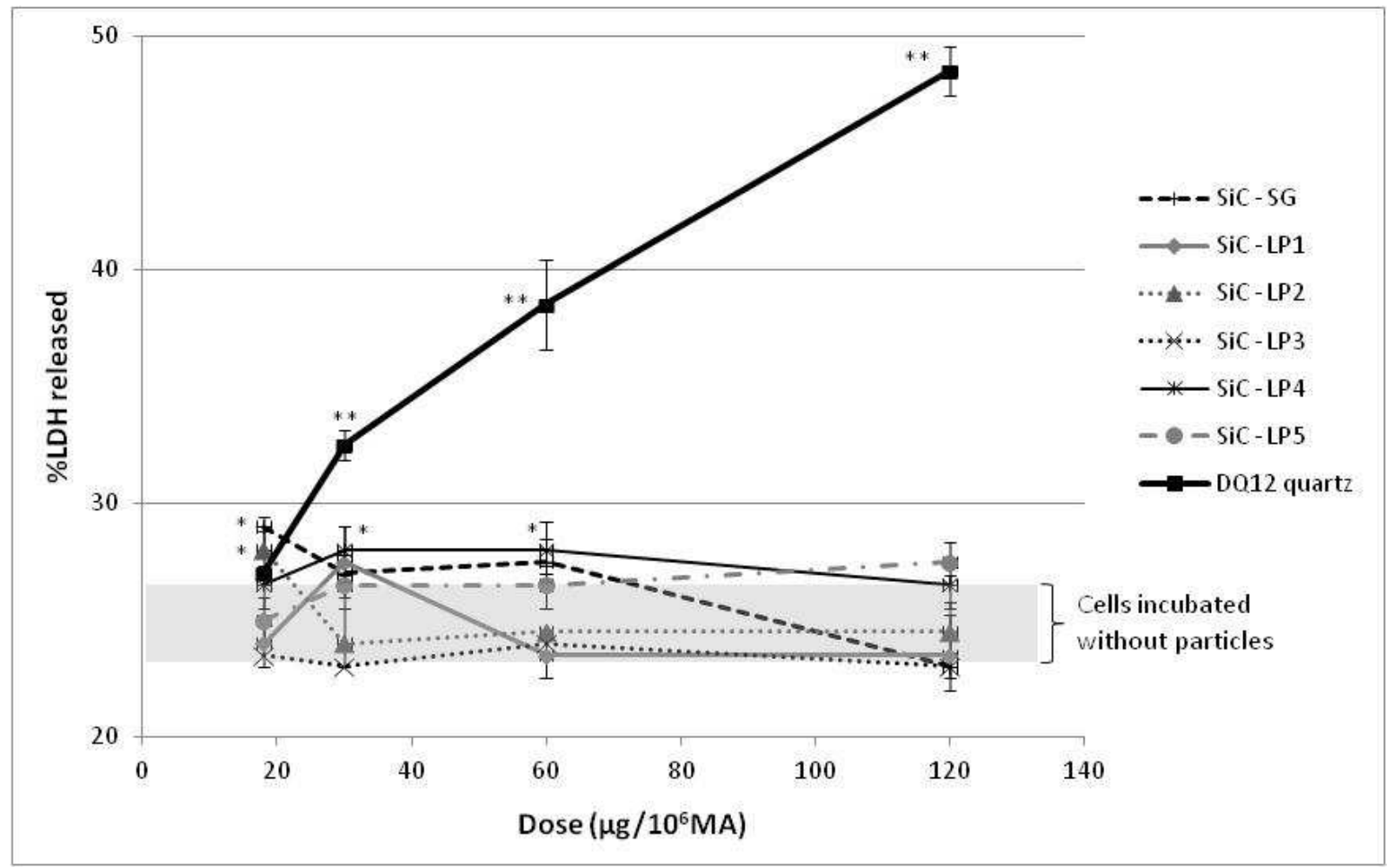


Fig. 3 Pro-inflammatory effect determined by the TNF- $\alpha$ production after a $24 \mathrm{H}$ incubation of cells with $\mathrm{SiC}$ nanoparticles. Doses were expressed in mass (A) or surface (B). Results are means of 3 independent experiments. Standard deviation and statistically significant differences from the negative control (cells incubated without nanoparticles) are also indicated: $* \mathrm{p}<0.05, * * \mathrm{p}<0.01$.

A

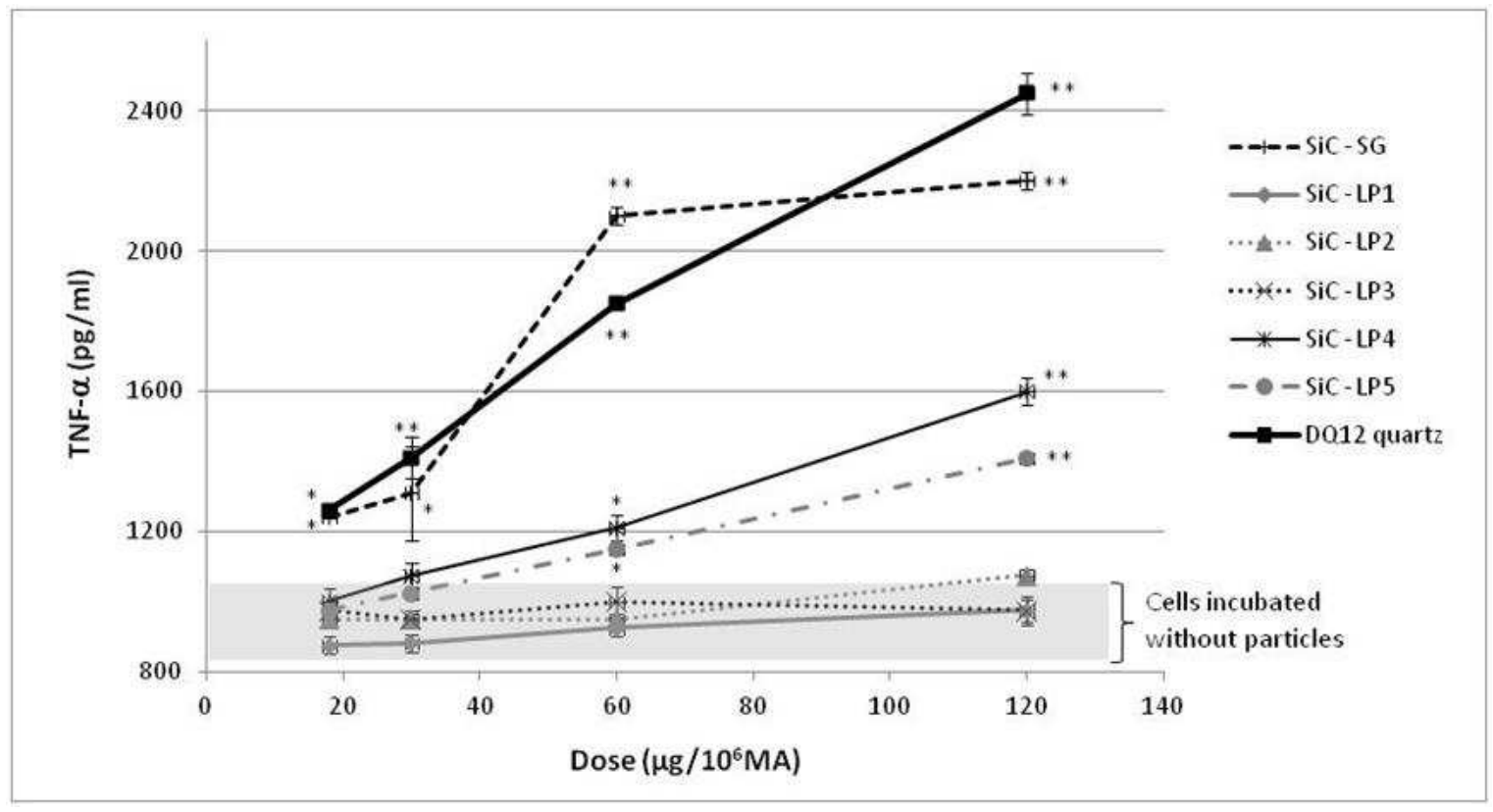

B

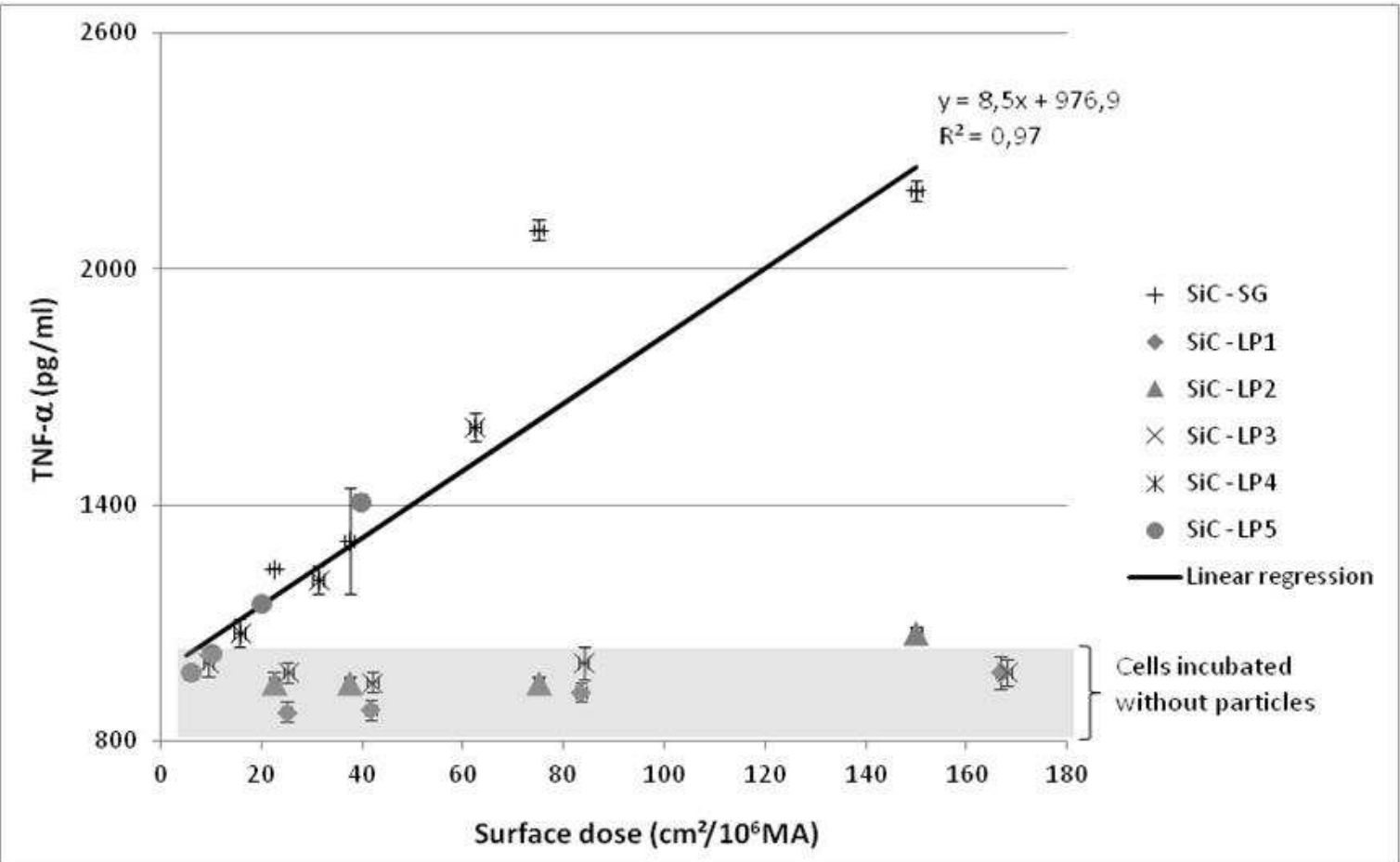


Fig. 4 Acute oxidative stress induced by the different $\mathrm{SiC}$ nanoparticles as assessed by the $\mathrm{H}_{2} \mathrm{O}_{2}$ production. Results are means of 3 independent experiments. Standard deviation and statistically significant differences from the negative control (cells incubated without nanoparticles) are also indicated: $* \mathrm{p}<0.05, * * \mathrm{p}<0.01$.

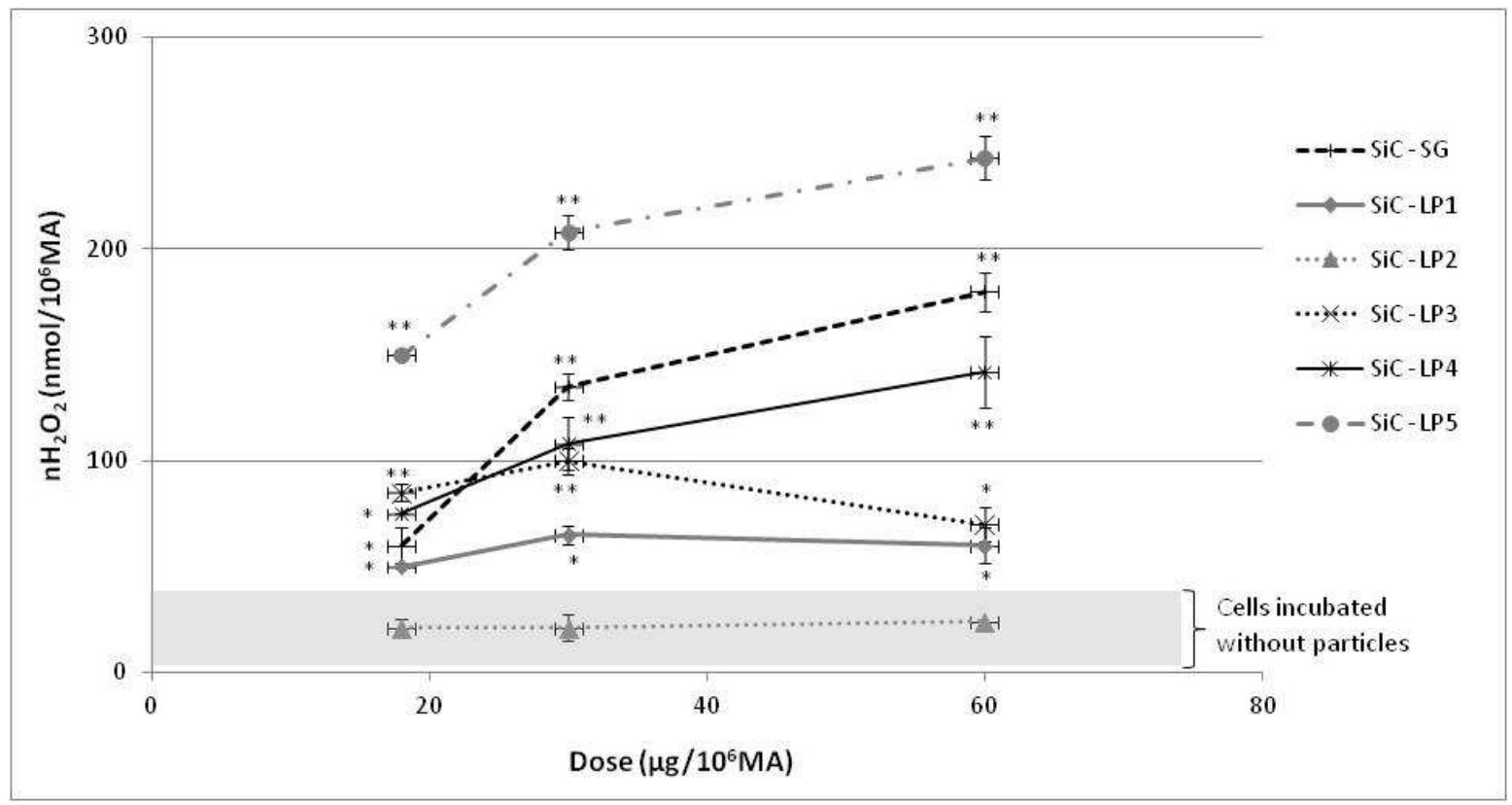


Fig. 5 Influence of iron impurities contained in the different $\mathrm{SiC}$ nanoparticles on the free radical release $\mathrm{A}) \mathrm{HO} \bullet$ and $\mathrm{B}$ ) $\mathrm{COO} \bullet$-, as determined by electron paramagnetic resonance.

A

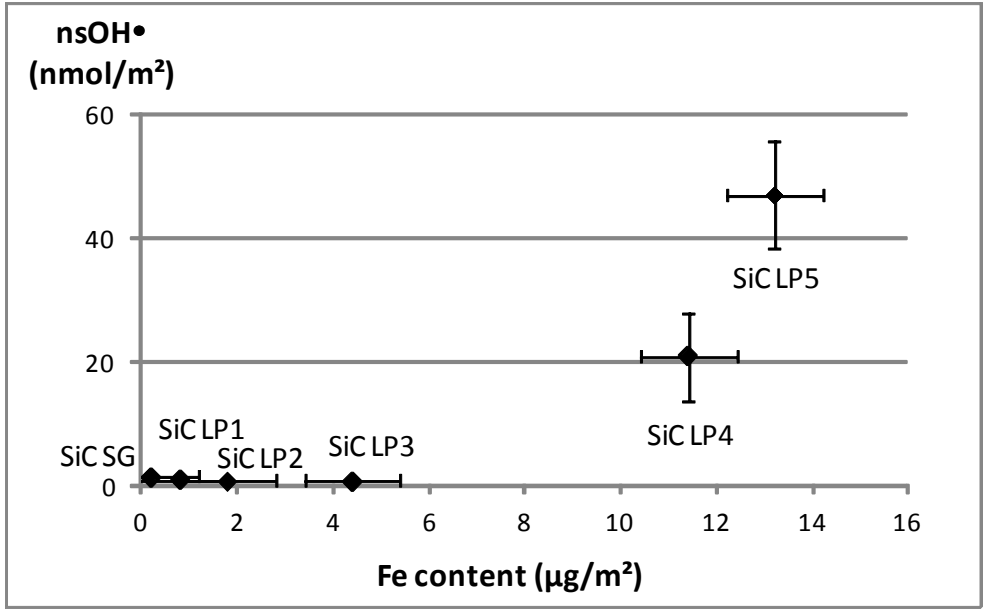

B

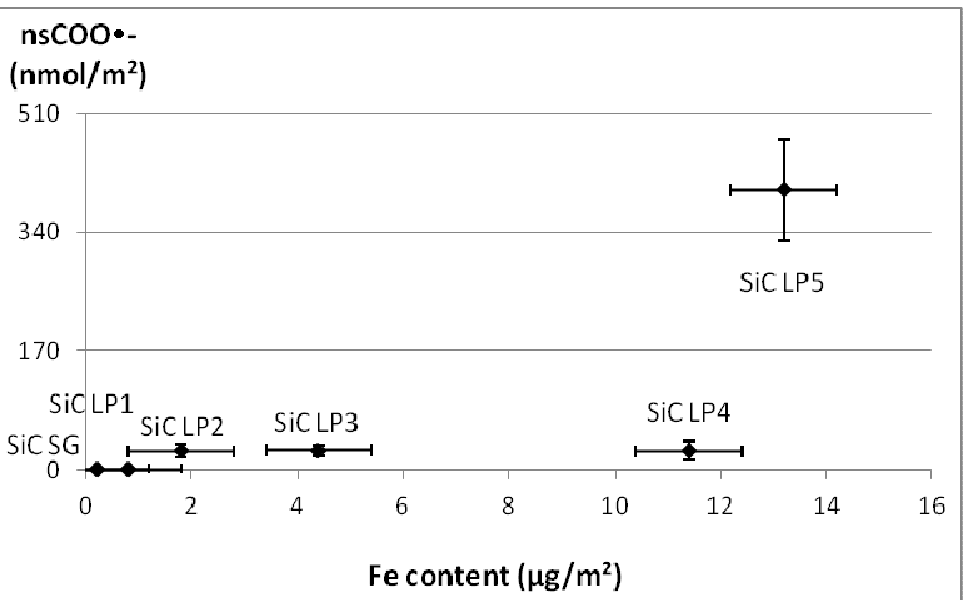


Table 1 Physico-chemical characteristics of the $6 \mathrm{SiC}$ nanoparticles

\begin{tabular}{|c|c|c|c|c|c|c|c|c|c|}
\hline Sample & $\underset{\left(\mathrm{g} / \mathrm{cm}^{3}\right)}{\rho}$ & $\begin{array}{c}\text { SSA } \\
\left(\mathrm{m}^{2} / \mathrm{g}\right)\end{array}$ & $\begin{array}{l}\text { BET size } \\
\quad(\mathbf{n m})\end{array}$ & Crystallite size & $\begin{array}{l}\text { Crystalline } \\
\text { phases }\end{array}$ & $\begin{array}{c}\text { O1s } \\
(\% \text { atomic })\end{array}$ & $\begin{array}{c}\mathrm{Fe} \\
(\mathbf{p p m})\end{array}$ & $\begin{array}{c}\mathrm{C} / \mathrm{Si} \\
\text { (atomic ratio) }\end{array}$ & Schematic representation \\
\hline SG & 3.2 & 125 & 15 & $\begin{array}{c}14 \mathrm{~nm} \\
\text { monocrystalline } \\
\text { nanograins }\end{array}$ & $\begin{array}{c}\beta-\mathrm{SiC}(\mathrm{SiC}-3 \mathrm{C}) \\
\alpha-\mathrm{SiC}<10 \%(\mathrm{SiC}-6 \mathrm{H})\end{array}$ & 8 & 0 & 0,88 & \\
\hline LP1 & 3.2 & 139 & 14 & $\begin{array}{c}4 \mathrm{~nm} \\
\text { polycrystalline } \\
\text { nanograins }\end{array}$ & $\beta-\mathrm{SiC}(\mathrm{SiC}-3 \mathrm{C})$ & 8 & 105 & 1 & \\
\hline LP2 & 3.1 & 125 & 15 & $\begin{array}{c}4 \mathrm{~nm} \\
\text { polycrystalline } \\
\text { nanograins }\end{array}$ & $\beta-\mathrm{SiC}(\mathrm{SiC}-3 \mathrm{C})$ & 7 & 200 & 1,21 & \\
\hline LP3 & 3.0 & 140 & 14 & $\begin{array}{c}4 \mathrm{~nm} \\
\text { polycrystalline } \\
\text { nanograins }\end{array}$ & $\beta-\mathrm{SiC}(\mathrm{SiC}-3 \mathrm{C})$ & $\begin{array}{c}14 \\
\text { (presence } \\
\text { of a } \mathrm{SiO}_{2} \text { layer) }\end{array}$ & 605 & 0,81 & $\mathrm{Fe}$ \\
\hline
\end{tabular}




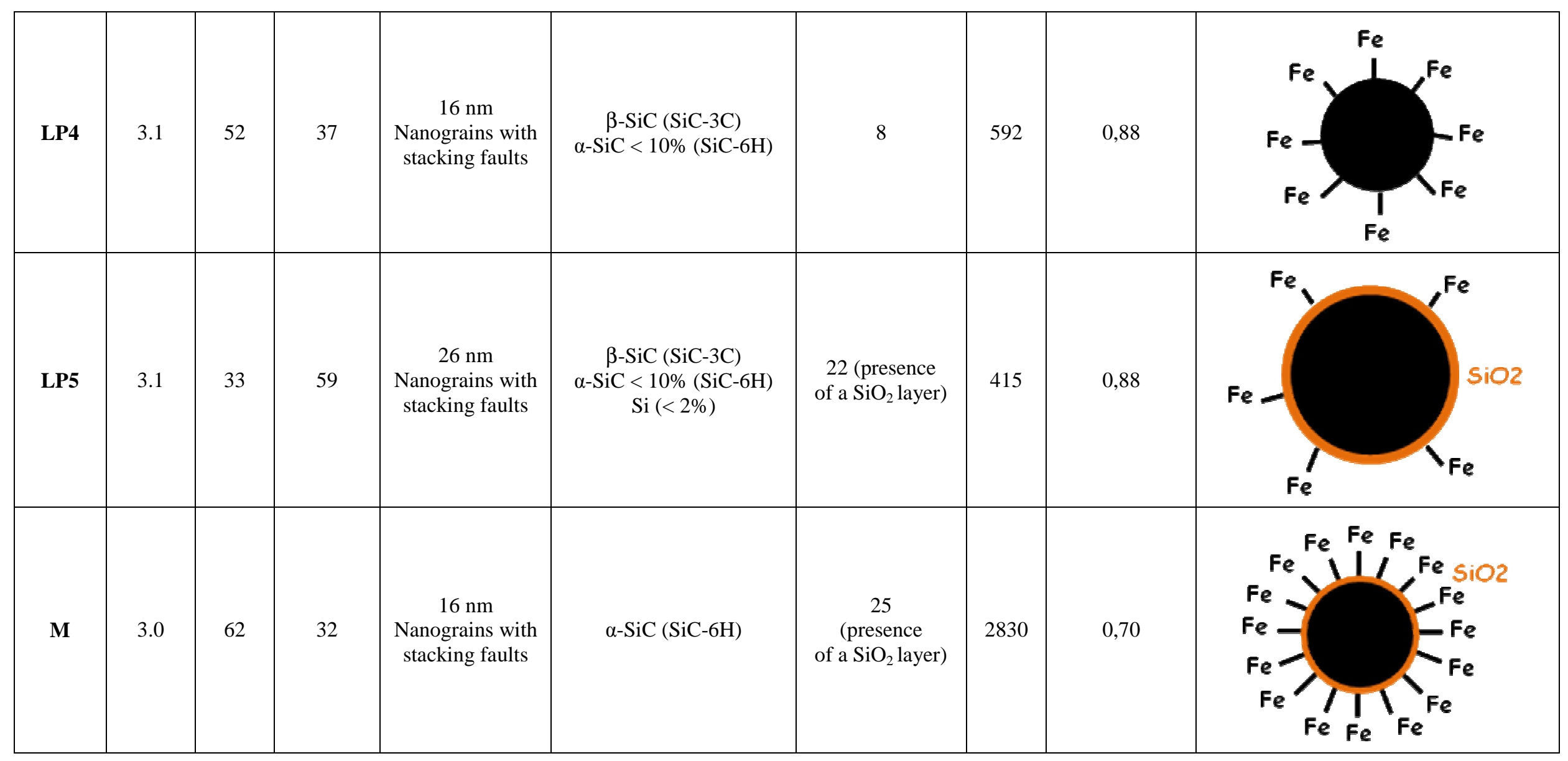


Table 2 Summary of the physico-chemical features influencing the biological activity of SiC nanoparticles.

\begin{tabular}{|c|c|c|c|c|c|c|c|}
\hline & & & \multicolumn{5}{|c|}{ Physico-chemical features of the $\mathrm{SiC}$ nanoparticles } \\
\hline & & & $\begin{array}{l}\text { Stoichiometry } \\
\text { (C/Si ratio) }\end{array}$ & Surface area & $\begin{array}{l}\text { Crystallinity (phase, } \\
\text { cristallite size) }\end{array}$ & Surface oxidation & {$[\mathrm{Fe}]$ at the surface } \\
\hline \multirow{4}{*}{$\begin{array}{c}\text { In vitro } \\
\text { cellular } \\
\text { responses }\end{array}$} & \multicolumn{2}{|c|}{ Cytotoxicity (LDH) } & \multicolumn{5}{|c|}{ No cytotoxic effect observed } \\
\hline & \multicolumn{2}{|c|}{$\begin{array}{c}\text { Pro-inflammatory effect } \\
(\mathrm{TNF} \alpha) \square\end{array}$} & & Linear correlation & Correlation & & \\
\hline & \multirow{2}{*}{$\begin{array}{l}\text { Oxidative } \\
\text { stress }\end{array}$} & $\begin{array}{c}\text { Cellular } \mathrm{H}_{2} \mathrm{O}_{2} \\
\text { production }\end{array}$ & & & & Correlation & \\
\hline & & $\begin{array}{c}\mathrm{HO}^{\bullet} \text { release } \\
\text { in cell free condition }\end{array}$ & & & & & $\begin{array}{l}\text { Correlation with } \\
\text { a threshold effect }\end{array}$ \\
\hline
\end{tabular}

